\title{
Treatment of Dystonia with Deep Brain Stimulation
}

\author{
Jill L. Ostrem ${ }^{* \dagger}$ and Philip A. Starr ${ }^{\dagger \dagger}$ \\ *Department of Neurology, University of California, San Francisco, California 94143; ${ }^{\dagger}$ Parkinson’s Disease Research, \\ Education and Clinical Center (PADRECC), San Francisco, California 94121; and Department of Neurological Surgery, \\ University of California, San Francisco, California 94143
}

\begin{abstract}
Summary: Pallidal deep brain stimulation (DBS) is an established treatment option for medically refractive dystonia. The mechanism by which globus pallidus pars interna (GPi) DBS improves dystonia is still unclear. Primary generalized dystonia usually responds well to this therapy, as recently confirmed in two well-designed, double-blind, controlled trials; however, predictors of outcome within this population are not well known. The role of GPi DBS in idiopathic cervical dystonia resistant to treatment with botulinum toxin, in tardive dystonia, and in some types of secondary dystonia
\end{abstract}

are emerging as populations of patients who may also benefit, but outcomes are not well documented. Serious complications from this therapy are rare. Future research will likely continue to address the most appropriate programming settings for various populations of dystonia, the mechanism by which DBS affects dystonia, and the possibility of alternative brain targets that might have less associated side effects or greater efficacy than the GPi. Key Words: Dystonia, deep brain stimulation, surgical outcomes, implantable device, neuromodulation, globus pallidus.

\section{INTRODUCTION}

Dystonia is a syndrome of sustained muscle contractions producing twisting and repetitive movements or abnormal postures often resulting in simultaneous contraction of both agonist and antagonist muscles. ${ }^{1}$ During voluntary movement, there is often activation of additional muscles not necessary for the intended movement.

Dystonia is classified as primary or idiopathic dystonia when it occurs without other neurologic signs and without brain abnormalities evidenced with magnetic resonance imaging (MRI). Dystonia is classified as secondary when it occurs in association with a lesion in the CNS, which can be caused by stroke, cerebral palsy, encephalitis, other environmental insults, or neurodegenerative diseases. In secondary dystonias, there is usually abnormality in cranial MRI or a known history of major CNS insult. Tardive dystonia is a special case of secondary dystonia that occurs following exposure to dopamine antagonist medications.

Dystonia is also commonly classified by anatomical distribution of the dystonia (focal, segmental, or gener-

Address correspondence and reprint requests to: Jill L. Ostrem, M.D., Assistant Professor of Neurology, University of California, San Francisco, 400 Parnassus Ave., Box 0348, San Francisco, CA 94143; E-mail: jill.ostrem@ucsf.edu. alized) or by age of symptom onset (juvenile or adult onset). Primary dystonias (especially generalized) are often hereditary and may be subdivided by genotype. There are several single-gene loci that have been associated with dystonia, the best known of which is the TORIA locus (previously DYT1). A three-base pair deletion at the TORIA locus is responsible for approximately $30 \%$ of juvenile-onset, primary generalized dystonias. ${ }^{2}$ In addition, involuntary dystonic movements can be described as mobile or phasic, in which there are rapid movements, or as fixed, in which longer lasting abnormal postures occur.

The pathophysiology of dystonia is not well understood. Several lines of evidence suggest that the basal ganglia play in important role in dystonia. Secondary dystonias are frequently associated with lesions of the putamen or globus pallidus. ${ }^{3}$ In functional imaging of primary dystonia, the putamen is a consistent site of metabolic abnormalities. ${ }^{4,5}$ Finally, single-neuron electrophysiologic recording in the globus pallidus pars interna (GPi) of dystonic humans shows abnormal discharge patterns and abnormal oscillatory activity, compared with control data from normal nonhuman primates. ${ }^{6-11}$ Some evidence from rodent models and from human functional imaging also suggests cerebellar involvement. $^{12}$ 
Dystonia may respond to anticholinergic medications, especially in childhood-onset primary dystonia, but anticholinergics are generally less effective and poorly tolerated in adults. ${ }^{13-15}$ A levodopa trial should be performed (especially in childhood-onset generalized dystonia) to rule out the possible diagnosis of doparesponsive dystonia (Segawa's dystonia). Tetrabenazine, antiepileptic, and benzodiazepine medications have been reported to improve dystonia in a small number of case reports. Oral baclofen is also often tried in patients with secondary dystonia. For focal or segmental dystonias, EMG-guided chemodenervation with botulinum toxin can be very effective and has been recommended by the National Institutes of Health in a consensus statement. ${ }^{16}$ For idiopathic cervical dystonia, botulinum toxin injection is considered the first-line therapy. ${ }^{17}$ Although less common with newer refined botulinum toxin products, some patients develop antibodies with prolonged use, reducing the effectiveness of this treatment. ${ }^{18}$ Despite these options, many generalized and some focal dystonia patients experience inadequate relief from medical therapy, at which time neurosurgical treatment options may be considered.

Neurosurgical intervention in dystonia has a rich history and includes a variety of procedures: peripheral denervation (typically in cervical dystonia), ${ }^{19}$ intrathecal baclofen pump implantation (typically in generalized dystonia with associated spasticity), ${ }^{20-22}$ and permanent lesioning of the basal ganglia (pallidotomy) or thalamus (thalamotomy). ${ }^{23,24}$ Currently, deep brain stimulation (DBS) is the most promising procedure performed for the treatment of dystonia and will be the focus of this review article.

\section{DEEP BRAIN STIMULATION}

The best-studied applications for DBS in movement disorders are thalamic stimulation for essential tremor and GPi or subthalamic nucleus (STN) stimulation for Parkinson's disease (PD). In 2003, the Medtronic Activa DBS device was granted limited Food and Drug Administration (FDA) approval in the United States for primary generalized and segmental dystonia, in patients ages 7 years or greater, under a humanitarian device exemption (HDE). Both GPi and STN targets were included in the HDE labeling. Most of the published work on DBS in dystonia focuses on GPi stimulation, although a small literature on thalamic and STN stimulation exists.

Deep brain stimulation alters neuronal discharge or axonal propagation (or both) in the target structure that is stimulated, although the exact mechanism by which this effect occurs is still unclear. The Medtronic Activa DBS system consists of an implantable pulse generator (IPG), an extension wire, and a four-contact brain lead which is placed into the desired target. Stimulation parameters are programmed noninvasively by the physician and can be adjusted as necessary for the patient's specific symptoms. In general, DBS has several advantages over ablative procedures, in that it is nondestructive, reversible, and adjustable. DBS also can be used safely bilaterally, without producing permanent speech, swallowing, or cognitive adverse effects, as have been seen with bilateral lesioning procedures. $^{23}$

\section{Surgical indications and patient evaluation}

Surgical indication. At most major surgical centers, patients are considered for surgical treatment if they meet the following criteria: 1) unequivocal diagnosis of primary or secondary dystonia, made by a movement disorders neurologist; 2) failure to manage dystonia with anticholinergic, antiepileptic, benzodiazepine medications, baclofen, or, in patients with focal or segmental dystonia, treatment failure after injection of botulinum toxin with appropriate muscle selection and dosing; 3) significant disability, despite optimal medical management (disability may be due to impaired movement, pain, social isolation, or a combination of these). Patients who are surgical candidates should undergo surgery prior to the onset of fixed orthopedic deformities, because these may limit functional improvement even when dystonia symptoms are ameliorated. ${ }^{25}$

Typically patients have a screening MRI scan of the brain (and, if indicated, the cervical spine), undergo neuropsychological and psychiatric assessments, and participate in a detailed videotaped clinical evaluation, including standardized dystonia rating scales, before surgery.

Rating scales for dystonia. A major difficulty in understanding the literature on surgical treatment of dystonia is the paucity of studies documenting the outcome of surgery in a reliable manner, using validated measures. For future studies, it will be critical that all patients be carefully studied with the use of standardized rating scales preferably performed by a movement disorders neurologist.

The most commonly used rating scale for generalized dystonia is the Burke-Fahn-Marsden Dystonia Rating Scale (BFMDRS). ${ }^{26,27}$ This scale is composed of a movement scale (based on an objective motor exam) and a disability scale (based on a patient interview). The BFMDRS motor score is a 120-point scale that rates the severity of dystonia in nine body regions, taking into account both the severity and frequency of the dystonic movements. This scale has shown excellent interrater reliability and is the preferred rating scale for generalized dystonia. ${ }^{26,27}$ The most commonly used rating scale for cervical dystonia is the Toronto Western Spasmodic Torticollis Rating Scale (TWSTRS), ${ }^{28}$ an 85-point scale with subscores for dystonia severity, functional disability, and pain. 
For both scales, a higher score indicates more severe dystonia. Although these rating scales result in objective outcome measures, they are limited in measuring fixed versus mobile dystonia and complex movements. Hence, there is always a need to perform videotaped exams to provide clear documentation of surgical outcome.

\section{Stereotactic targeting and microelectrode recording}

The optimal technique for accurate placement of DBS electrodes for dystonia has not been defined. Nearly all groups used MRI-based stereotactic localization. Some surgeons use stereotaxy as the sole localization technique and perform the implantation with the patient under general anesthesia, ${ }^{29}$ whereas others supplement stereotactic localization with microelectrode recording and intraoperative test stimulation in awake patients. ${ }^{25}$

At our center, adults with dystonia usually have lead implantation under monitored local anesthesia, but children are operated upon under general anesthesia. After stereotactic headframe placement and after MR imaging has been obtained, targeting is performed using surgical planning software. For GPi DBS, the target point for the tip of the DBS lead is typically at the base of the posterior globus pallidus, immediately superior to the dorsal border of the optic tract in a coronal plane $2 \mathrm{~mm}$ anterior to the mid-commissural point. The spatial coordinates of the GPi show great interindividual variability, with the lateral coordinate for the lead tip ranging from 16 to 23 $\mathrm{mm}$ from midline. An example of typical lead location is shown in Figure 1.

Single-unit microelectrode recording is useful to help confirm correct placement of the DBS lead, although most multicenter trials of DBS for dystonia have not used this technique. GPi neurons in dystonia discharge at lower frequencies than in $\mathrm{PD}$, and the distinction between neuronal firing rate in the external versus internal pallidal segments is not as pronounced as in parkinsonian patients. $^{6-11,25}$ To confirm electrode location and test for possible unacceptable stimulation-induced side effects, intraoperative test stimulation is also performed after the lead has been placed, to check thresholds for stimulationinduced activation of the corticobulbar, corticospinal, and optic tracts.

There are a few published case series in which the location of the electrically active contacts associated with good clinical outcome have been well documented..$^{25,30-32}$ The active contact location associated with major clinical improvement appears to be in the posterior $\mathrm{GPi}, 3 \mathrm{~mm}$ to $4 \mathrm{~mm}$ from the pallidocapsular border, and $2 \mathrm{~mm}$ to $5 \mathrm{~mm}$ dorsal to the optic tract (FIG. 1). In this region, an effect of stimulation on the external pallidum as well as the internal pallidum cannot be ruled out.

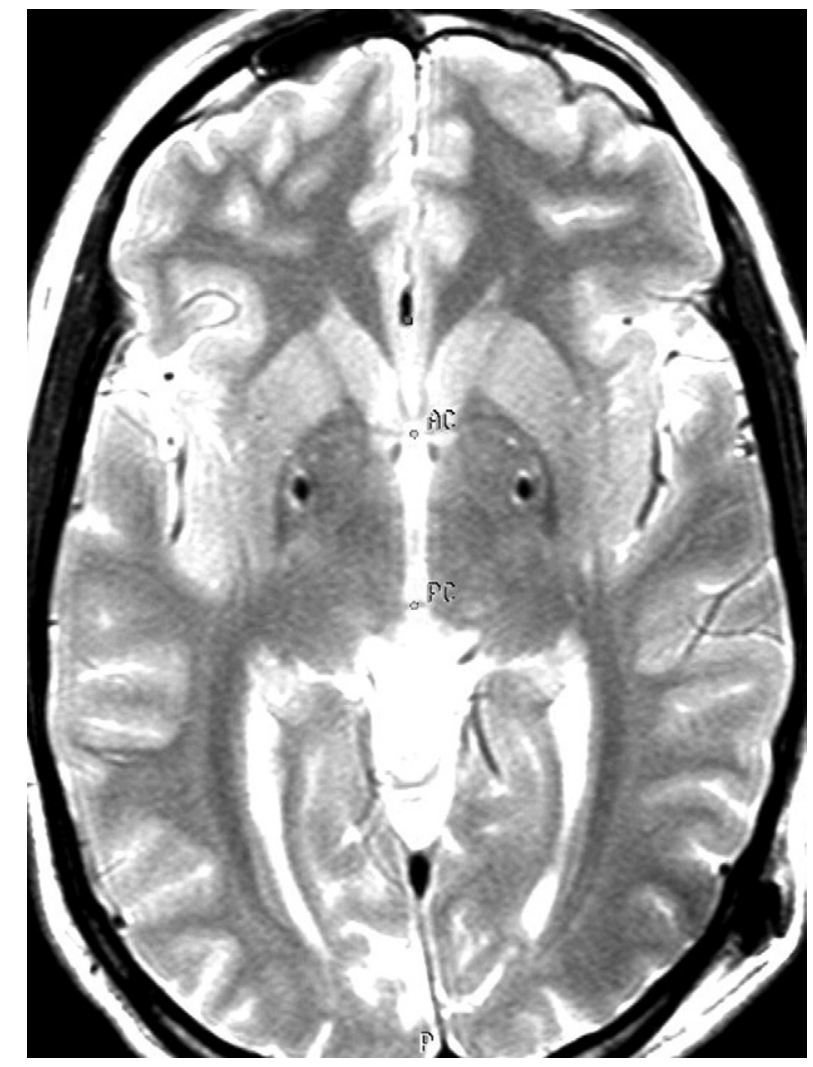

FIG. 1. Postoperative axial T2-weighted MRI demonstrating typical bilateral GPi positioning of deep brain stimulation leads in a 24-year-old patient, positive for the TOR1A mutation (previously DYT1), with generalized dystonia who experienced a $60 \%$ improvement in BFMDRS movement score 6 months after surgery.

\section{Programming}

Postoperative programming of the DBS system is more challenging than in patients with PD or essential tremor, because improvement may take months to occur. Some groups have reported early improvement (days to weeks) after programming, usually in conditions involving mobile dystonia or pain, ${ }^{32-34}$ but most patients experience a slower improvement after programming (months). Given this delay in the effect of programming, the decision of when to make changes in contact choice or other parameters is often difficult and subjective.

In general, stimulation currents for GPi DBS in dystonia are somewhat higher than for GPi DBS in PD, and consistently higher than for STN DBS in PD. In many series, pulse widths are $>180 \mu \mathrm{s}$, whereas those typically used in PD are $60 \mu$ s to $90 \mu$ s. Some groups, however, are reporting excellent outcomes in dystonia with the use of smaller pulse widths, ${ }^{35,36}$ and a recent article comparing various pulse widths in primary generalized dystonia failed to show any difference in outcome when using short, medium, and long pulse-width durations. ${ }^{37}$ High-frequency stimulation $(130-185 \mathrm{~Hz})$ has also been used historically, with effective outcomes. Recently, low-frequency stimulation has been shown to 
be effective in primary generalized dystonia $(60 \mathrm{~Hz}){ }^{38}$ and in cervical dystonia $(50-60 \mathrm{~Hz}) .{ }^{39} \mathrm{We}$ have preliminary evidence to suggest that lower frequency stimulation $(60 \mathrm{~Hz})$ may not be as effective in patients with cranial-cervical dystonia (personal observation). The optimal frequency setting may depend on the type of dystonia, a question that deserves additional study. Overall, the high pulse widths and voltages needed in many dystonia patients can result in frequent battery changes (as often as 1 to 2 years when using the Medtronic Kinetra dual channel pulse generator).

\section{Clinical outcome}

Clinical outcomes after GPi DBS are described in the following sections, according to the type of dystonia.

\section{DBS IN PRIMARY DYSTONIA}

\section{Primary generalized dystonia}

Patients with medically refractory primary generalized dystonia, both with and without the TORIA mutation (here referred to as $\mathrm{DYT}^{+}$and $\mathrm{DYT}^{-}{ }^{-}$), are the largest group to be studied with GPi DBS. We have found 249 cases reported in the literature to date, with the outcomes of surgery summarized in Table 1. ${ }^{25,30,32,35,38,40-56} \mathrm{Al}$ most all studies have reported some improvement with DBS; however, the degree of improvement varies widely across studies, ranging from $21 \%$ to $95 \%$ in the BFMDRS movement score, with most studies showing $60 \%$ to $70 \%$ improvement. Most of these cases were reported in small, open-label, nonblinded studies.

Recently, two important prospective, randomized multicenter double-blind European trials of GPi DBS were published. Vidailhet et al. ${ }^{32}$ studied 22 patients with primary generalized dystonia who were evaluated preoperatively, and at 3, 6, and 12 months postoperatively. A mean improvement of $54 \%$ in the BFMDRS movement score and $44 \%$ in the BFMDRS disability score were seen at 12 months with chronic stimulation, relative to baseline. ${ }^{32}$ At 3 months, patients underwent videotaped double-blind evaluations in the presence and absence of neurostimulation (up to 10 hours, if tolerated) on alternate days. When stimulated, patients showed a statistically significant mean improvement of $29 \%$ in the BFMDRS movement score, compared with the unstimulated condition. ${ }^{32}$

Subsequently, Kupsch et al. ${ }^{41}$ reported a series of 40 patients with primary segmental and primary generalized dystonia treated with bilateral GPi DBS with randomization to either neurostimulation or sham stimulation for 3 months. At 3 months, patients receiving neurostimulation had a mean improvement of $39.9 \%$ in BFMDRS movement scores and 38\% in BFMDRS disability scores, compared with $4.9 \%$ and $11 \%$ in the sham group. After chronic stimulation for 6 months, patients showed a mean improvement of $45 \%$ in BFMDRS movement scores and $41 \%$ in BFMDRS disability scores. These two trials $^{32,41}$ provided the first class I evidence for the use of bilateral pallidal DBS in dystonia.

The largest series of cases of GPi-DBS in primary generalized dystonia with greater than 1 year follow-up was provided by Coubes et al., ${ }^{49}$ who found a $79 \%$ mean improvement in the BFMDRS movement score in 31 patients 2 years after surgery. A recent long-term follow-up study by Vidailhet et al. ${ }^{40}$ also showed continued mean improvement in BFMDRS movement scores and disability scores (58\% and $46 \%$, respectively) in their previously reported 22 patients.

Most series describe continued improvement in dystonia symptoms over the first year. ${ }^{32}$ Loss of benefit of GPi DBS after 1 year has only rarely been reported ${ }^{53}$; however, some reports describe subsets of patients with only modest improvement or less commonly no meaningful improvement. ${ }^{32}$ Possible reasons for failure include suboptimal DBS lead location, suboptimal DBS programming, or incorrect diagnosis at time of surgery (e.g., patients with unrecognized secondary dystonia, heredodegenerative syndromes, or dystonia-plus syndromes).

Currently, the ability to predict outcomes preoperatively is limited. Initial reports described patients with the TORIA mutation as having better outcomes than patients without the mutation, ${ }^{53,57}$ but more recent reports indicate that both groups have a similar benefit from GPi DBS. ${ }^{32,41,49}$ Age of onset of dystonia has also not been found consistently to be predictive of outcome. Patients with longer disease duration may be at increased risk of developing secondary fixed contractures and may not have as great a functional outcome after surgery. ${ }^{38}$ Also, some studies have shown more improvement in appendicular dystonia (limb) than axial dystonia (speech and swallowing) symptoms.

For now, pallidal DBS remains an extremely powerful and important therapy, with dramatic improvements seen in most patients. Specific predictors of outcome will remain elusive, however, until larger series of patients are studied in blinded, well-designed clinical trials, clearly documenting lead location, programming parameters, and detailed patient characterization.

\section{Primary cervical dystonia}

Patients with medically intractable primary cervical dystonia who have failed botulinum toxin therapy may also benefit from pallidal DBS. There is one report of unilateral GPi DBS successfully treating cervical dystonia, ${ }^{58}$ but most published cases have involved bilateral stimulation, including the first reported series of three patients by Krauss et al. ${ }^{59}$ in 1999 . To date, approximately 53 cases of patients with GPi DBS for cervical dystonia have been published in the literature, 
TABLE 1. Published Results of GPi DBS for Primary Dystonia in Series with $>5$ Patients

Percent

\begin{tabular}{|c|c|c|c|c|c|c|}
\hline Type of Dystonia & $N$ & Scale (Subscale) & Baseline Score & FU Time (mo) & FU Score & Improvement \\
\hline \multicolumn{7}{|l|}{ Vercueil et al. ${ }^{48}(2001)^{a}$} \\
\hline Primary generalized* & 1 & BFMDRS (m/d) & NA & 12 & NA & $67 / 81$ \\
\hline Primary generalized* & 1 & BFMDRS (m/d) & NA & 6 & NA & $70 / 50$ \\
\hline Primary DYT1 ${ }^{+}$ & 1 & BFMDRS (m/d) & NA & 12 & NA & $86 / 86$ \\
\hline Primary DYT1 ${ }^{-}$ & 1 & BFMDRS (m/d) & NA & 24 & NA & $41 / 43$ \\
\hline Cranial-cervical & 1 & BFMDRS (m/d) & NA & 6 & NA & $66 / 66$ \\
\hline \multicolumn{7}{|l|}{ Krauss et al. ${ }^{61}$ (2002) } \\
\hline Cervical & 5 & TWSTRS (s/d/p) & $20.5 / 40.5 / 6$ & 20 & $\begin{array}{c}7.5 / 12.7 / \\
3\end{array}$ & $62 / 69 / 50$ \\
\hline \multicolumn{7}{|l|}{ Bereznai et al. ${ }^{30}$ (2002) } \\
\hline Segmental & 3 & BFMDRS (m) & NA & $3-12$ & NA & $72.5^{\dagger}$ \\
\hline Primary DYT1 ${ }^{+}$ & 1 & Tsui scale & NA & $3-12$ & NA & 45 \\
\hline Cervical (1 MS) & 2 & NA & NA & $3-12$ & NA & \\
\hline \multicolumn{7}{|c|}{ Yianni, Bain, Gregory et al. ${ }^{45}$ (2003). ${ }^{\text {b }}$} \\
\hline Primary $\mathrm{DYT}^{+}$ & 2 & BFMDRS (m) & NA & 12 & NA & $85^{\ddagger}$ \\
\hline Primary DYT1 ${ }^{-}$ & 11 & BFMDRS (m) & NA & & NA & $46^{\ddagger}$ \\
\hline Cervical & 7 & TWSTRS (s/d/p) & $21.3 / 21.7 / 15.1$ & & $10 / 14 / 8.3$ & $50 / 38 / 43$ \\
\hline \multicolumn{7}{|c|}{ Yianni, Bain, Giladi et al. ${ }^{51}$ (2003). } \\
\hline Generalized & 12 & BFMDRS (m) & 79.7 & $4-184$ & 45.3 & 46 \\
\hline Cervical & 7 & TWSTRS (t) & 57.8 & $12-2$ & 23.0 & 59 \\
\hline \multicolumn{7}{|l|}{ Cif et al. ${ }^{44}$ (2003) } \\
\hline Primary DYT1 ${ }^{+}$ & 15 & BFMDRS (m/d) & $60.8 / 16.7$ & $24-36>$ & $14.2 / 5.7$ & $71 / 63$ \\
\hline Primary DYT1- & 17 & BFMDRS (m/d) & $56.5 / 16.4$ & $24-36$ & $15.1 / 9.5$ & $74 / 49$ \\
\hline \multicolumn{7}{|l|}{ Krauss et al. ${ }^{52}$ (2003) } \\
\hline Primary DYT1- & 2 & BFMDRS (m) & 81 & 24 & 21.5 & 73 \\
\hline \multicolumn{7}{|l|}{ Kupsch et al. ${ }^{96}$ (2003) } \\
\hline Primary DYT $1^{+}$ & 1 & BFMDRS (m) & 34.5 & $3-12$ & 27 & 22 \\
\hline Primary DYT1 ${ }^{-}$ & 3 & & 40 & & 20 & 50 \\
\hline Segmental & 1 & & 32 & & 19 & 41 \\
\hline \multicolumn{7}{|l|}{ Katayama et al. ${ }^{54}(2003)^{\mathrm{c}}$} \\
\hline Primary & 5 & BFMDRS (m) & $18-62$ & 6 & $4-23$ & $51-92$ \\
\hline \multicolumn{7}{|l|}{ Coubes et al. ${ }^{49}(2004)^{\mathrm{d}}$} \\
\hline Primary DTY1+ & 17 & BFMDRS (m) & 62.6 & 24 & 12.4 & 83 \\
\hline Primary DYT1 ${ }^{-}$ & 14 & FMDRS (m) & 56.3 & 24 & 13.4 & 75 \\
\hline \multicolumn{7}{|l|}{ Vayssière et al. ${ }^{31}$ (2004) } \\
\hline Primary generalized* & 19 & BFMDRS & NA & NA & NA & $>80$ \\
\hline \multicolumn{7}{|l|}{ Eltahawy et al. ${ }^{57}(2004)^{\mathrm{e}}$} \\
\hline Primary DYT1 ${ }^{+}$ & 1 & BFMDRS (m) & 88 & 6 & 66 & 25 \\
\hline Primary DYT1 ${ }^{-}$ & 1 & BFMDRS (m) & 48 & & 16 & 21 \\
\hline Cervical & 3 & TWSTRS (t) & 37.7 & & 16 & 57 \\
\hline \multicolumn{7}{|l|}{ Krause et al. ${ }^{53}$ (2004) } \\
\hline Primary DYT $1^{+}$ & 4 & BFMDRS (m) & 72 & $12-66$ & 34 & 53 \\
\hline Primary DYT1 ${ }^{-}$ & 6 & BFMDRS (m) & 73.9 & & 50 & 32 \\
\hline Cervical & 1 & BFMDRS (m) & 6 & & 6 & 0 \\
\hline \multicolumn{7}{|l|}{ Vidailhet et al. ${ }^{32}$ (2005) } \\
\hline Primary DYT1 $^{+}$ & 75 & BFMDRS (m/d) & $55.1 / 14.72$ & 12 & 26.1/85 & $53 / 45.6$ \\
\hline Primary DYT1 & 1 & BFMDRS (m/d) & 41.96/10.2 & & $18.7 / 5.5$ & $55.4 / 45$ \\
\hline \multicolumn{7}{|l|}{ Bittar et al. $^{43}(2005)^{\mathrm{f}}$} \\
\hline Primary $\mathrm{DYT}^{+}$ & 2 & BMFDRS $(\mathrm{t})$ & 103.8 & 24 & 55.8 & $46^{\S}$ \\
\hline Primary DYT1 ${ }^{-}$ & 4 & TWSTRS (t) & 57.8 & 24 & 23.7 & 59 \\
\hline Cervical & 6 & & & & & \\
\hline \multicolumn{7}{|l|}{ Zorzi et al. ${ }^{55}$ (2005) } \\
\hline Primary DYT1 ${ }^{+}$ & 1 & BFMDRS (m/d) & $47 / 11$ & 4 & $14 / 6$ & $70 / 45$ \\
\hline Primary DYT1 ${ }^{-}$ & 8 & BFMDRS (m/d) & $68.9 / 17.9$ & 19.1 & $46.5 / 12.6$ & $32 / 37$ \\
\hline
\end{tabular}


TABLE 1. Continued

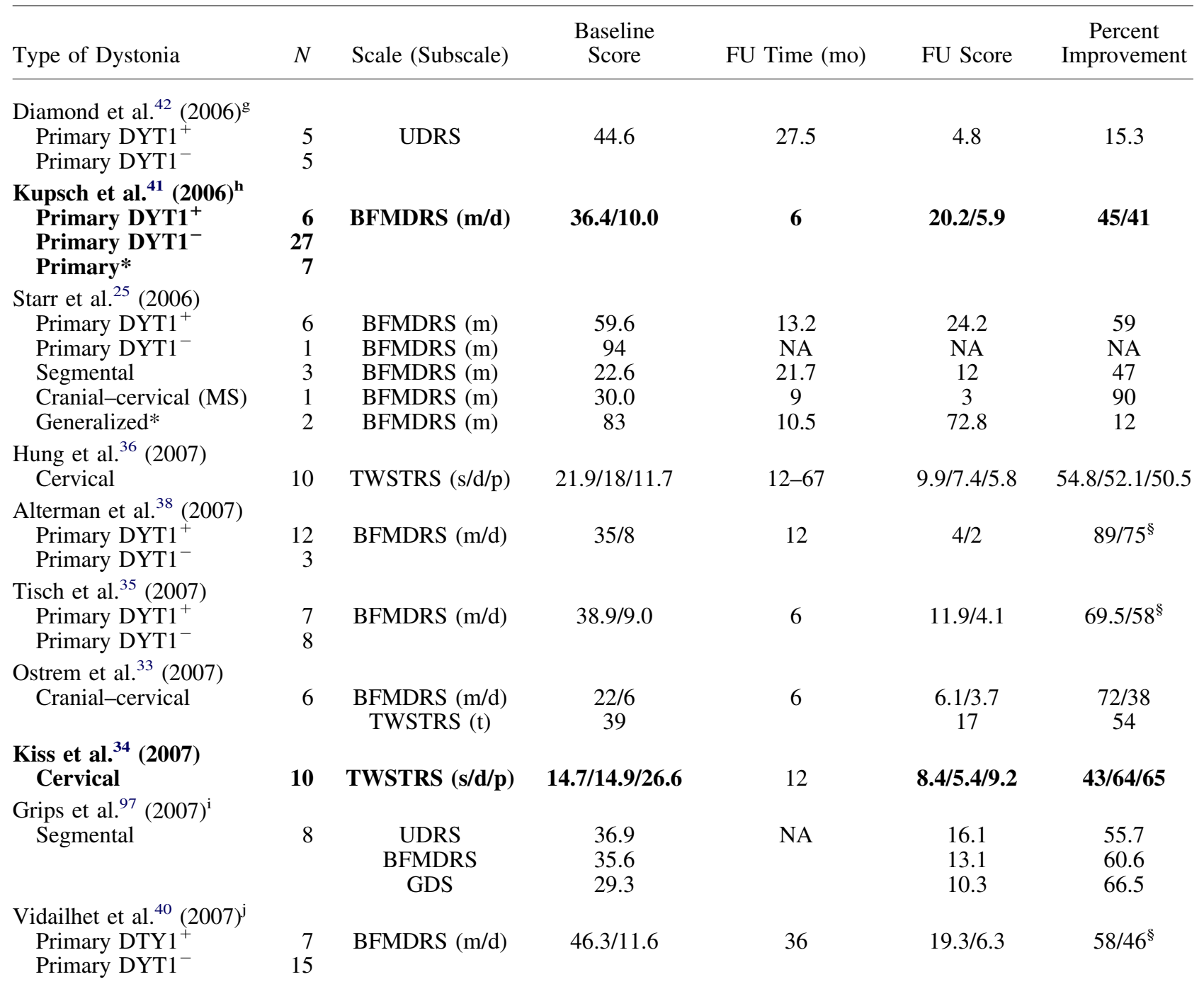

Series with Class 1 evidence are highlighted in bold type.

BFMDRS $=$ Burke-Fahn-Marsden Dystonia Rating Scale; $\mathrm{DYT}^{+}=$negative for mutation in TORIA (previously DYT1); ${ }^{\mathrm{DYT}} 1^{-}=$ negative for TOR1A mutation; FU = follow-up; GDS = Global Dystonia Scale; MS = Meige syndrome; NA = not available; TWSTRS = Toronto Western Spasmodic Torticollis Rating Scale; UDRS = Unified Dystonia Rating Scale. Subscales and scoring: $\mathrm{d}=\mathrm{disability} ; \mathrm{m}=$ movement; $\mathrm{p}=$ pain; $\mathrm{s}=$ severity; $\mathrm{t}=$ total score.

*Unknown subtype. ${ }^{\dagger}$ Primary and segmental groups analyzed together. ${ }^{*}$ Estimated. ${ }^{\S} \mathrm{DYT} 1{ }^{+}$and DYT $1{ }^{-}$groups analyzed together. ${ }^{\text {a Series }}$ also included 12 patients treated with thalamic DBS alone and 3 with thalamic DBS then GPi DBS; 2 patients had no follow-up. ${ }^{\text {b Same }}$ patients as Yianni et al. ${ }^{51}$ One patient bilateral thalamotomy, one patient unilateral pallidotomy. ${ }^{\mathrm{d}}$ Longer term follow-up from Cif et al. ${ }^{44}$ (2003). ${ }^{\mathrm{e}}$ Study also includes pallidotomy patients. ${ }^{\mathrm{f}}$ Both primary groups analyzed together; 12 -month follow-up data gathered. ${ }^{\mathrm{g}}$ Two patients with pallidotomy; outcome for all patients analyzed together. ${ }^{\mathrm{h}}$ All groups analyzed together. ${ }^{\mathrm{i}}$ All patients previously reported. ${ }^{\mathrm{j}}$ Same patients as Vidailhet et al. ${ }^{32}$ (2005).

most described as individual case reports or small series. $^{30,34,36,39,43,51,57,58,60-62}$

Outcome data again are variable, ranging from $43 \%$ to 76\% improvement in TWSTRS scores (Table 1). Recently, a well-designed, blinded-rater study reported outcomes in 10 patients at 12 months after surgery, showing a $44 \%, 64 \%$, and $65 \%$ mean improvement in TWSTRS severity, disability, and pain subscores, respectively. ${ }^{34}$ Hung et al. $^{36}$ reported long-term sustained benefit in a series of 10 cervical dystonia patients up to 3 years postoperatively. Although most reports suggest overall improvement, there are several reports suggesting only minor improvement in head and neck position, but significant improvement in associated neck pain.

There is one report of a patient with cervical dystonia who showed improvement after 5 years of chronic bilateral GPi DBS, with sustained improvement for at least 6 months after stimulation was discontinued. ${ }^{63} \mathrm{~A}$ similar case of cranial dystonia has also been described. ${ }^{64}$ Such sustained benefit raises the possibility that GPi DBS in 
focal dystonia may permanently correct abnormal motor circuits. In most cases, however, patients remain stimulator dependent. Although DBS is clearly promising, considerably more data are needed to better define the role of DBS in cervical dystonia, including patient selection, optimal programming settings, and long-term outcomes.

\section{Primary cranial-cervical dystonia (Meige syndrome)}

There are now several reports of GPi DBS in patients with medication-refractory, idiopathic cranialcervical dystonia (Meige syndrome). In the 13 cases reported, outcomes range from $45 \%$ to $80 \%$ improvement in BFMDRS at short follow-up times (typically $<6$ months). ${ }^{30,33,48,65-68}$ In a series of six patients, we reported a mean improvement of $71 \%$ in BFMDRS movement score in an open-label trial 6 months postoperatively. ${ }^{33}$ Some patients, however, developed reversible stimulation-induced bradykinesia in previously nondystonic limbs after prolonged GPi DBS. ${ }^{33}$ Whether adjustments in programming can optimize dystonia control without the development of subtle bradykinesia, or if stimulation in other brain targets (e.g., STN) minimizes this adverse effect, remains to be evaluated.

\section{DBS IN SECONDARY DYSTONIAS}

\section{Heredodegenerative syndromes}

Limited data suggest that patients with symptoms of dystonia associated with some of the heredodegenerative syndromes may improve substantially in the short term with GPi DBS. Castelnau et al. ${ }^{69}$ published a series of six patients with pantothenate kinase-associated neurodegeneration (PKAN), demonstrating a 75\% mean improvement in BFMDRS movement scores, with follow-up from 6 to 42 months. Three other PKAN cases in the literature also reflect similar short-term improvement in dystonia symptoms. ${ }^{53,70,71}$

\section{Tardive dystonia}

Thus far, there have been limited results with patients undergoing GPi DBS for tardive dystonia. Since 2001, there have only been 25 cases reported, all showing some improvement in BFMDRS movement scores (range, $35 \%-73 \%$ ) at various postoperative time points. ${ }^{25,51,53,57,72}$ A recently published, multicenter double-blind trial of GPi DBS in 10 patients with medically refractory tardive dyskinesia showed a $50 \%$ significant mean improvement in the extrapyramidal symptoms rating scale score ${ }^{73}$ using blinded assessments after 6 months of stimulation. ${ }^{74}$ Most reports also comment on the quick improvement in symptoms (within days) after the DBS is activated.

\section{Dystonia-plus syndromes}

Studies of GPi DBS in myoclonic dystonia have shown improvement in both dystonic and myoclonic features of this disorder. ${ }^{51,75,76}$ Also, a case of X-linked dystonia of parkinsonism has also been reported to respond, ${ }^{77}$ whereas a case of rapid-onset dystonia-parkinsonism was reported to not respond. ${ }^{78}$

\section{Other secondary dystonia}

Summarizing the outcomes of GPi DBS in other forms of secondary dystonia is difficult, because of the inherent heterogeneity of this population of patients, small numbers of cases reported, and variability in outcome measures used. In general, secondary dystonia does not respond as consistently or as markedly as primary dystonia. Cases treated with GPi DBS include posttraumatic, ${ }^{25,48,51,53,79,80}$ postanoxic or cerebral palsy associated, ${ }^{25,48,52,53,55}$ postencephalitic, ${ }^{55,57}$ and poststroke cases. There are also a few case reports of DBS for dystonia associated with multiple sclerosis, ${ }^{51}$ Huntington's disease, ${ }^{57}$ and basal ganglia calcification. ${ }^{55}$

Clearly, the outcome assessment in secondary dystonia is complicated by the heterogeneity of this population, with mixed etiologies and often with coexisting neurological deficits. Our early experience suggests that phasic movements may improve but fixed dystonic postures do not. In this population, although dystonia improvement may be minimal, the patient and family might still find the improvement meaningful.

\section{MECHANISM OF DBS ON DYSTONIA}

The mechanism of action of GPi DBS in dystonia is not well understood. The GPi is the major output nucleus of the basal ganglia, influencing supplementary motor cortex via the ventrolateral thalamus, and the brain stemspinal cord via the pedunculopontine nucleus. The rationale for GPi DBS in dystonia has been empiric rather than theoretical, growing from earlier work on pallidotomy for dystonia, as well as the positive results from pallidotomy and pallidal DBS for dystonic symptoms in patients with Parkinson's disease. There is evidence that globus pallidus neuronal activity in dystonia is abnormal. ${ }^{6-11}$ GPi DBS is presumed to override the existing abnormality, although it clearly does not restore normal function. Functional imaging indicates that GPi DBS corrects abnormal hypermetabolism in supplementary motor areas, ${ }^{81}$ presumably by ameliorating the abnormal influence of GPi on thalamocortical pathways.

\section{COMPLICATIONS AND ALTERNATIVE TARGETS}

Deep brain stimulation is relatively safe in the hands of neurosurgeons experienced in performing this proce- 
TABLE 2. Cases in the Literature of Subthalamic Nucleus Deep Brain Stimulation for Dystonia

\begin{tabular}{|c|c|c|c|c|c|c|}
\hline Type of Dystonia & $N$ & Scale & $\begin{array}{l}\text { Baseline } \\
\text { Score }\end{array}$ & $\begin{array}{l}\text { FU Time } \\
\text { (mo) }\end{array}$ & FU Score & $\begin{array}{c}\text { Percent } \\
\text { Improvement }\end{array}$ \\
\hline $\begin{array}{l}\text { Pastor-Gómez et al. } .^{92} \text { (2003) } \\
\text { Generalized }\end{array}$ & 1 & NA & NA & NA & NA & NA \\
\hline $\begin{array}{l}\text { Detante et al. } .^{93}(2004) \\
\text { Primary generalized } \\
\text { PKAN }\end{array}$ & $\begin{array}{r}13 \\
3\end{array}$ & NA & NA & $\begin{array}{l}3 \\
3\end{array}$ & NA & No improvement \\
\hline $\begin{array}{l}\text { Chou et al. }{ }^{91}(2005) \\
\text { Cervical dystonia and ET }\end{array}$ & 1 & TWSTRS (s/d) & $14 / 20$ & 6 & $3 / 0$ & $79 / 100$ \\
\hline $\begin{array}{l}\text { Zhang et al. } .^{98}(2006)^{\mathrm{a}} \\
\text { Tardive dystonia } \\
\text { Antiemetics } \\
\text { Neonatal anoxia } \\
\text { Lesion in lentiform nuclei } \\
\text { Neonatal jaundice } \\
\text { Posttraumatic thal infarct } \\
\text { NA and jaundice } \\
\text { No cause }\end{array}$ & $\begin{array}{l}1 \\
1 \\
2 \\
1 \\
1 \\
1 \\
1 \\
1\end{array}$ & $\begin{array}{l}\text { BFMDRS }(\mathrm{m}) \\
\text { BFMDRS }(\mathrm{m}) \\
\text { BFMDRS }(\mathrm{m})\end{array}$ & $\begin{array}{l}98.8 \\
26.5 \\
76\end{array}$ & $\begin{array}{l}3 \\
3 \\
6\end{array}$ & $\begin{array}{l}8 \\
2 \\
7\end{array}$ & $\begin{array}{l}91.9 \\
90.6 \\
\text { Did poorly } \\
90.8 \\
\text { Did poorly } \\
\text { Did poorly } \\
\text { Did poorly } \\
\text { Did poorly }\end{array}$ \\
\hline Kleiner-Flisman et al. ${ }^{90}$ (2007 & & & & & & \\
\hline Segmental-major cervical & 1 & $\begin{array}{l}\text { BFMDRS }(\mathrm{m} / \mathrm{d}) \\
\text { TWSTRS }(\mathrm{s} / \mathrm{d} / \mathrm{p}) \\
\text { BFMDRS }(\mathrm{m} / \mathrm{d}) \\
\text { TWSTRS }(\mathrm{s} / \mathrm{d} / \mathrm{p})\end{array}$ & $\begin{array}{c}36.5 / 5 \\
31 / 27 / 14 \\
\text { NA/NA } \\
21 / 16 / 17\end{array}$ & 12 & $\begin{array}{c}29 / 10 \\
23 / 20 / 5.5 \\
\text { NA/NA } \\
12 / 5 / 14.25\end{array}$ & $\begin{array}{c}21 / 50 \\
26 / 26 / 61 \\
\text { NA/NA } \\
43 / 69 / 16\end{array}$ \\
\hline Segmental-major cervical & 1 & $\begin{array}{l}\text { BFMDRS }(\mathrm{m} / \mathrm{d}) \\
\text { TWSTRS }(\mathrm{s} / \mathrm{d} / \mathrm{p})\end{array}$ & $\begin{array}{c}53 / 14 \\
26 / 27 / 15.25\end{array}$ & & $\begin{array}{c}59 / 17 \\
28 / 24 / 18.25\end{array}$ & $\begin{array}{c}-11 /-21 \\
-8 / 11 /-20\end{array}$ \\
\hline Primary generalized & 1 & $\begin{array}{l}\text { BFMDRS }(\mathrm{m} / \mathrm{d}) \\
\text { TWSTRS }(\mathrm{s} / \mathrm{d} / \mathrm{p})\end{array}$ & $\begin{array}{c}43 / 5 \\
19 / 8 / 3.5\end{array}$ & & $\begin{array}{c}12 / 3 \\
14 / 1 / 0\end{array}$ & $\begin{array}{c}72 / 40 \\
26 / 88 / 100\end{array}$ \\
\hline $\begin{array}{l}\text { Sun et al. }{ }^{94}(2007)^{\mathrm{c}} \\
\text { Primary generalized } \\
\text { Tardive dystonia }\end{array}$ & $\begin{array}{r}12 \\
2\end{array}$ & BFMDRS & NA & $6-42$ & NA & $76-100$ \\
\hline $\begin{array}{l}\text { Novek et al. }{ }^{95}(2007)^{\mathrm{d}} \\
\text { Primary generalized }\end{array}$ & 1 & BFMDRS (m/d) & NA & 29 & NA & $23 / 42$ \\
\hline
\end{tabular}

BFMDRS = Burke-Fahn-Marsden Dystonia Rating Scale; ET = essential tremor; FU = follow-up; NA = not available; PKAN = pantothenate kinase-associated neurodegeneration; TWSTRS = Toronto Western Spasmodic Torticollis Rating Scale. Subscales and scoring: $\mathrm{d}=$ disability $\mathrm{m}=$ movement $\mathrm{p}=$ pain; $\mathrm{s}=$ severity; $\mathrm{t}=$ total $\mathrm{score}$; thal $=$ thalamic.

aBilateral STN, 6 cases; unilateral STN, 2 cases; left STN and right GPi, 1 case. ${ }^{\mathrm{b}}$ Also performed 3 months follow-up and used blinded raters.

${ }^{\mathrm{c}}$ Groups reported together. ${ }^{\mathrm{d}}$ Patient with previous left pallidotomy.

dure. The most common serious complications with DBS include stroke, infection, and lead fracture. Most of the rates quoted for these complications come from mixed populations of patients having DBS, not specifically for dystonia. For all patients considering DBS surgery, we typically quote a $1 \%$ risk of hemorrhagic stroke per brain hemisphere, a 5\% risk of device-related infection severe enough to require further surgery for hardware removal, and a $1 \%$ per year risk of lead fracture.

Combining the experience from the two recent, blinded trials of GPi DBS for primary generalized and segmental dystonia ${ }^{40,41}$ and the largest published series by Coubes et al. ${ }^{49}$ allows an evaluation of adverse effects in a total of 93 patients followed for 6 to 36 months. In this cohort of patients, there were no reports of stroke. In our series, currently at 70 patients, one patient suffered a symptomatic venous hemorrhage, and two have had small asymptomatic hemorrhages. ${ }^{25}$ Typically, dystonia patients are younger than patients undergoing DBS for essential tremor and PD, which may reduce the surgical risk for hemorrhagic stroke.

In the three trials just mentioned, ${ }^{40,41,49}$ there were a total of six cases of infection ( 6 of 93, or 6\%), with four of them requiring partial or complete hardware removal. In our series, 2 of the 70 patients have had infections requiring device removal (3\%), both of them children under 10 years of age with severe generalized dystonia. ${ }^{82}$

Yianni et al. ${ }^{83}$ found a disproportionate risk of lead fractures and lead migration (singly or in combination) in their dystonia patients (18.4\%), compared with all patients implanted with DBS systems (5.3\%). This high rate of hardware complications may be explained by severe phasic neck movements resulting in increased stress on the hardware in dystonia. In the combined cohort of 93 patients mentioned above, ${ }^{40,41,49} 4$ patients experienced this problem (4\%). We had 2 of 70 dystonia 
patients $(3 \%)$ develop lead fractures; with a mean follow-up of approximately 3 years, but the incidence will undoubtedly increase with longer follow-up times.

Many other questions remain for the application of DBS for dystonia. The best brain target is not yet clear. The results of thalamic stimulation in dystonia, reported for approximately 20 cases, have been disappointing. ${ }^{48,72,84-87}$ One exception is that occupational dystonias, such as writer's cramp, appears to be uniquely sensitive to thalamic surgery, which suggests a different pathophysiology from primary dystonias. ${ }^{88,89}$ Although GPi is currently the most popular brain target, the STN as a target for dystonia has not been fully explored ${ }^{90-95}$ (Table 2), and the theoretical basis for selecting any one target over another is poor.

\section{SUMMARY}

GPi DBS is an important treatment option for medically refractory dystonia. The mechanism by which GPi DBS improves dystonia is still unclear. Accurate placement of DBS leads into the posterioventral GPi is important for optimal outcomes. Primary generalized dystonia can respond dramatically; however, predictors of outcome within this population are not well-known. The positive role of GPi DBS in idiopathic cervical dystonia, tardive dystonia, and some cases of secondary dystonia is also emerging, but outcomes are not well documented, and additional studies are needed. For neurosurgeons experienced in performing this procedure, serious complications from DBS therapy are rare. Future research will need to continue to address the most appropriate programming settings, the mechanism by which DBS affects dystonia, and the possibility of alternative brain targets (e.g., STN) that might have lesser associated side effects or greater efficacy than GPi DBS for dystonia.

Acknowledgments: This work was supported in part by the National Institutes of Health (Grant K08 NS002201) and by the Parkinson's Disease Research, Education, and Clinical Center (PADRECC) at the San Francisco Veterans Affairs Medical Center.

\section{REFERENCES}

1. Fahn S, Bressman SB, Marsden CD. Classification of dystonia. Adv Neurol 1998;78:1-10.

2. Ozelius LJ, Hewett JW, Page CE, Bressman SB, Kramer PL, Shalish C, de Leon D, Brin MF, Raymond D, Corey DP, Fahn S, Risch NJ, Buckler AJ, Gusella JF, Breakefield XO. The early-onset torsion dystonia gene (DYT1) encodes an ATP-binding protein. Nat Genet 1997;17:40-48.

3. Marsden CD, Obeso JA, Zarranz JJ, Lang AE. The anatomical basis of symptomatic hemidystonia. Brain 1985;108:463-483.

4. Asanuma K, Ma Y, Okulski J, et al. Decreased striatal D2 receptor binding in non-manifesting carriers of the DYT1 dystonia mutation. Neurology 2005;64:347-349.

5. Eidelberg D, Moeller JR, Antonini A, et al. Functional brain networks in DYT1 dystonia. Ann Neurol 1998;44:303-312.
6. Starr PA, Rau GM, Davis V, et al. Spontaneous pallidal neuronal activity in human dystonia: comparison with Parkinson's disease and normal macaque. J Neurophysiol 2005;93:3165-3176.

7. Silberstein P, Kühn AA, Kupsch A, et al. Patterning of globus pallidus local field potentials differs between Parkinson's disease and dystonia. Brain 2003;126:2597-2608.

8. Vitek JL, Chockkan V, Zhang JY, et al. Neuronal activity in the basal ganglia in patients with generalized dystonia and hemiballismus. Ann Neurol 1999;46:22-35.

9. Merello M, Cerquetti D, Cammarota A, et al. Neuronal globus pallidus activity in patients with generalised dystonia. Mov Disord 2004;19:548-554.

10. Sanghera MK, Grossman RG, Kalhorn CG, Hamilton WJ, Ondo WG, Jankovic J. Basal ganglia neuronal discharge in primary and secondary dystonia in patients undergoing pallidotomy. Neurosurgery 2003;52:1358-1373.

11. Tang JK, Moro E, Mahant N, et al. Neuronal firing rates and patterns in the globus pallidus internus of patients with cervical dystonia differ from those with Parkinson's disease. J Neurophysiol 2007;98:720-729.

12. LeDoux MS, Lorden JF. Abnormal spontaneous and harmalinestimulated Purkinje cell activity in the awake genetically dystonic rat. Exp Brain Res 2002;145:457-467.

13. Burke RE, Fahn S. Double-blind evaluation of trihexyphenidyl in dystonia. Adv Neurol 1983;37:189-192.

14. Burke RE, Fahn S, Marsden CD. Torsion dystonia: a double-blind, prospective trial of high-dosage trihexyphenidyl. Neurology 1986; 36:160-164.

15. Nutt JG, Hammerstad JP, deGarmo P, Carter J. Cranial dystonia: double-blind crossover study of anticholinergics. Neurology 1984; 34:215-217.

16. The National Institutes of Health Consensus Development Conference on Clinical Use of Botulinum Toxin Consensus Panel. Botulinum toxin. Consens Statement 1990;8(8):1-20.

17. Albanese A, Barnes MP, Bhatia KP, et al. A systematic review on the diagnosis and treatment of primary (idiopathic) dystonia and dystonia plus syndromes: report of an EFNS/MDS-ES Task Force. Eur J Neurol 2006;13:433-444.

18. Jankovic J. Botulinum toxin: clinical implication of antigenicity and immunoresistance. In: Brin MF, Jankovic J, Hallett M, Scientific and therapeutic aspects of botulinum toxin. Philadelphia: Lippincott Williams \& Wilkins, 2002:409-415.

19. Bertrand CM. Selective peripheral denervation for spasmodic torticollis: surgical technique, results, and observations in 260 cases. Surg Neurol 1993;40:96-103.

20. Ford B, Greene P, Louis ED, et al. Use of intrathecal baclofen in the treatment of patients with dystonia. Arch Neurol 1996;53: $1241-1246$

21. Walker RH, Danisi FO, Swope DM, Goodman RR, Germano IM, Brin MF. Intrathecal baclofen for dystonia: benefits and complications during six years of experience. Mov Disord 2000;15:12421247.

22. Albright AL, Barry MJ, Shafton DH, Ferson SS. Intrathecal baclofen for generalized dystonia. Dev Med Child Neurol 2001;43: 652-657.

23. Cooper IS. 20-year follow-up study of the neurosurgical treatment of dystonia musculorum deformans. Adv Neurol 1976;14:423452.

24. Andrew J, Fowler CJ, Harrison MJG. Stereotaxic thalamotomy in 55 cases of dystonia. Brain 1983;106:981-1000.

25. Starr PA, Turner RS, Rau G, et al. Microelectrode-guided implantation of deep brain stimulators into the globus pallidus internus for dystonia: techniques, electrode locations, and outcomes. J Neurosurg 2006;104:488-501.

26. Comella CL, Leurgans S, Wuu J, Stebbins GT, Chmura T; Dystonia Study Group. Rating scales for dystonia: a multicenter assessment. Mov Disord 2003;18:303-312.

27. Burke RE, Fahn S, Marsden CD, Bressman SB, Moskowitz C, Friedman J. Validity and reliability of a rating scale for the primary torsion dystonias. Neurology 1985;35:73-77.

28. Comella CL, Stebbins GT, Goetz CG, Chmura TA, Bressman SB, Lang AE. Teaching tape for the motor section of the Toronto 
Western Spasmodic Torticollis Scale. Mov Disord 1997;12: $570-575$.

29. Vayssière N, Hemm S, Zanca M, et al. Magnetic resonance imaging stereotactic target localization for deep brain stimulation in dystonia children. J Neurosurg 2000;93:784-790.

30. Bereznai B, Steude U, Seelos K, Bötzel K. Chronic high frequency globus pallidus internus stimulation in different types of dystonia: a clinical, video, and MRI report of six patients presenting with segmental, cervical, and generalized dystonia. Mov Disord 2002; $17: 138-144$.

31. Vayssière N, van der Gaag N, Cif L, et al. Deep brain stimulation for dystonia confirming a somatotopic organization in the globus pallidus internus. J Neurosurg 2004;101:181-188.

32. Vidailhet M, Vercueil L, Houeto JL, et al. Bilateral deep-brain stimulation of the globus pallidus in primary generalized dystonia. Lancet Neurol 2005;352:459-467.

33. Ostrem JL, Marks WJ Jr, Volz MM, Heath SL, Starr PA. Pallidal deep brain stimulation in patients with cranial-cervical dystonia (Meige syndrome). Mov Disord 2007;22:1885-1891.

34. Kiss ZH, Doig-Beyaert K, Eliasziw M, Tsui J, Haffenden A, Suchowersky O; Functional and Stereotactic Section of the Canadian Neurosurgical Society; Canadian Movement Disorders Group. The Canadian multicentre study of deep brain stimulation for cervical dystonia. Brain 2007;130:2879-2886.

35. Tisch S, Zrinzo L, Limousin P, et al. Effect of electrode contact location on clinical efficacy of pallidal deep brain stimulation in primary generalised dystonia. J Neurol Neurosurg Psychiatry 2007;78:1314-1319.

36. Hung SW, Hamani C, Lozano AM, et al. Long-term outcome of bilateral pallidal deep brain stimulation for primary cervical dystonia. Neurology 2007;68:457-459.

37. Vercueil L, Houeto JL, Krystkowiak P, et al. Effects of pulse width variations in pallidal stimulation for primary generalized dystonia. J Neurol 2007;254:1533-1537.

38. Alterman RL, Miravite J, Weisz D, Shils JL, Bressman SB, Tagliati M. Sixty hertz pallidal deep brain stimulation for primary torsion dystonia. Neurology 2007;69:681-688.

39. Goto S, Mita S, Ushio Y. Bilateral pallidal stimulation for cervical dystonia: an optimal paradigm from our experiences. Stereotact Funct Neurosurg 2002;79:221-227.

40. Vidailhet M, Vercueil L, Houeto JL, et al. Bilateral, pallidal, deep-brain stimulation in primary generalised dystonia: a prospective 3 year follow-up study. Lancet Neurol 2007;6:223-229.

41. Kupsch A, Benecke R, Müller J, et al. Pallidal deep-brain stimulation in primary generalized or segmental dystonia. N Engl J Med 2006;355:1978-1990.

42. Diamond A, Shahed J, Azher S, Dat-Vuong K, Jankovic J. Globus pallidus deep brain stimulation in dystonia. Mov Disord 2006;21: 692-695.

43. Bittar RG, Yianni J, Wang S, et al. Deep brain stimulation for generalised dystonia and spasmodic torticollis. J Clin Neurosci 2005;12:12-16.

44. Cif L, El Fertit H, Vayssière N, et al. Treatment of dystonic syndromes by chronic electrical stimulation of the internal globus pallidus. J Neurosurg Sci 2003;47:52-55.

45. Yianni J, Bain PG, Gregory RP, et al. Post-operative progress of dystonia patients following globus pallidus internus deep brain stimulation. Eur J Neurol 2003;10:239-247.

46. Vesper J, Klostermann F, Funk T, Stockhammer F, Brock M. Deep brain stimulation of the globus pallidus internus (GPi) for torsion dystonia: a report of two cases. Acta Neurochir Suppl 2002;79: $83-88$.

47. Tronnier VM, Fogel W. Pallidal stimulation for generalized dystonia: report of three cases. J Neurosurg 2000;92:453-456.

48. Vercueil L, Pollak P, Fraix V, et al. Deep brain stimulation in the treatment of severe dystonia. J Neurol 2001;248:695-700.

49. Coubes P, Cif L, El Fertit H, et al. Electrical stimulation of the globus pallidus internus in patients with primary generalized dystonia: long-term results. J Neurosurg 2004;101:189-194.

50. Eltahawy HA, Saint-Cyr J, Giladi N, Lang AE, Lozano AM. Primary dystonia is more responsive than secondary dystonia to pallidal interventions: outcome after pallidotomy or pallidal deep brain stimulation. Neurosurgery 2004;54:613-619.
51. Yianni J, Bain P, Giladi N, et al. Globus pallidus internus deep brain stimulation for dystonic conditions: a prospective audit. Mov Disord 2003; 18:436-442.

52. Krauss JK, Loher TJ, Weigel R, Capelle HH, Weber S, Burgunder JM. Chronic stimulation of the globus pallidus internus for treatment of non-DYT1 generalized dystonia and choreoathetosis: 2-year follow-up. J Neurosurg 2003;98:785-792.

53. Krause M, Fogel W, Kloss M, Rasche D, Volkmann J, Tronnier V. Pallidal stimulation for dystonia. Neurosurgery 2004;55:1361-1368; discussion 1368-1370.

54. Katayama Y, Fukaya C, Kobayashi K, Oshima H, Yamamoto T. Chronic stimulation of the globus pallidus internus for control of primary generalized dystonia. Acta Neurochir Suppl 2003;87:125128.

55. Zorzi G, Marras C, Nardocci N, et al. Stimulation of the globus pallidus internus for childhood-onset dystonia. Mov Disord 2005; 20:1194-1200.

56. Kumar R, Dagher A, Hutchison WD, Lang AE, Lozano AM Globus pallidus deep brain stimulation for generalized dystonia: clinical and PET investigation. Neurology 1999;53:871-874.

57. Eltahawy HA, Saint-Cyr J, Giladi N, Lang AE, Lozano AM. Primary dystonia is more responsive than secondary dystonia to pallidal interventions: outcome after pallidotomy or pallidal deep brain stimulation. Neurosurgery 2004;54:613-619; discussion 619-621.

58. Işlekel S, Zileli M, Zileli B. Unilateral pallidal stimulation in cervical dystonia. Stereotact Funct Neurosurg 1999;72:248-252.

59. Krauss JK, Pohle T, Weber S, Ozdoba C, Burgunder J. Bilateral stimulation of the globus pallidus internus for treatment of cervical dystonia. Lancet 1999;354:837-838.

60. Kulisevsky J, Lleó A, Gironell A, Molet J, Pascual-Sedano B, Parés P. Bilateral pallidal stimulation for cervical dystonia: dissociated pain and motor improvement. Neurology 2000;55:17541755.

61. Krauss JK, Loher TJ, Pohle T, et al. Pallidal deep brain stimulation in patients with cervical dystonia and severe cervical dyskinesias with cervical myelopathy. J Neurol Neurosurg Psychiatry 2002; 72:249-256

62. Kiss ZH, Doig K, Eliasziw M, Ranawaya R, Suchowersky O. The Canadian multicenter trial of pallidal deep brain stimulation for cervical dystonia: preliminary results in three patients. Neurosurg Focus 2004;17(1):E5.

63. Goto S, Yamada K. Long term continuous bilateral pallidal stimulation produces stimulation independent relief of cervical dystonia. J Neurol Neurosurg Psychiatry 2004;75:1506-1507.

64. Hebb MO, Chiasson P, Lang AE, Brownstone RM, Mendez I. Sustained relief of dystonia following cessation of deep brain stimulation. Mov Disord 2007;22:1958-1962.

65. Muta D, Goto S, Nishikawa S, et al. Bilateral pallidal stimulation for idiopathic segmental axial dystonia advanced from Meige syndrome refractory to bilateral thalamotomy. Mov Disord 2001;16: $774-777$.

66. Houser M, Waltz T. Meige syndrome and pallidal deep brain stimulation. Mov Disord 2005;20:1203-1205.

67. Foote KD, Sanchez JC, Okun MS. Staged deep brain stimulation for refractory craniofacial dystonia with blepharospasm: case report and physiology. Neurosurgery 2005;56:E415; discussion E415.

68. Opherk C, Gruber C, Steude U, Dichgans M, Bötzel K. Successful bilateral pallidal stimulation for Meige syndrome and spasmodic torticollis. Neurology 2006;66:E14.

69. Castelnau P, Cif L, Valente EM, et al. Pallidal stimulation improves pantothenate kinase-associated neurodegeneration. Ann Neurol 2005;57:738-741.

70. Starr PA, Marks WJ, Lindsey N, Byrd D, Rau G, Turner R. Pallidal deep brain stimulation for dystonia: technical approach and magnetic resonance imaging verified electrode locations. Neurosurgery 2003;53:494. Abstract.

71. Umemura A, Jaggi JL, Dolinskas CA, Stern MB, Baltuch GH Pallidal deep brain stimulation for longstanding severe generalized dystonia in Hallervorden-Spatz syndrome: case report. J Neurosurg 2004;100:706-709.

72. Trottenberg T, Paul G, Meissner W, Maier-Hauff K, Taschner C, 
Kupsch A. Pallidal and thalamic neurostimulation in severe tardive dystonia. J Neurol Neurosurg Psychiatry 2001;70:557-559.

73. Chouinard G, Margolese H. Manual for the Extrapyramidal Symptom Rating Scale (ESRS) [Erratum in: Schizophr Res 2006;85: 305]. Schizophr Res 2005;76:247-265.

74. Damier P, Thobois S, Witjas T, et al. Bilateral deep brain stimulation of the globus pallidus to treat tardive dyskinesia. Arch Gen Psychiatry 2007;64:170-176.

75. Magariños-Ascone CM, Regidor I, Martínez-Castrillo JC, GómezGalán M, Figueiras-Méndez R. Pallidal stimulation relieves myoclonus-dystonia syndrome. J Neurol Neurosurg Psychiatry 2005; 76:989-991.

76. Cif L, Valente EM, Hemm S, et al. Deep brain stimulation in myoclonus-dystonia syndrome. Mov Disord 2004;19:724-727.

77. Evidente VG, Lyons MK, Wheeler M, et al. First case of Xlinked dystonia-parkinsonism ("Lubag") to demonstrate a response to bilateral pallidal stimulation. Mov Disord 2007;22: $1790-1793$.

78. Deutschlander A, Asmus F, Gasser T, Steude U, Bötzel K. Sporadic rapid-onset dystonia-parkinsonism syndrome: failure of bilateral pallidal stimulation. Mov Disord 2005;20:254-257.

79. Loher TJ, Hasdemir MG, Burgunder JM, Krauss JK. Long-term follow-up study of chronic globus pallidus internus stimulation for posttraumatic hemidystonia. J Neurosurg 2000;92:457-460.

80. Chang JW, Choi JY, Lee BW, Kang UJ, Chung SS. Unilateral globus pallidus internus stimulation improves delayed onset posttraumatic cervical dystonia with an ipsilateral focal basal ganglia lesion. J Neurol Neurosurg Psychiatry 2002;73:588-590.

81. Detante O, Vercueil L, Thobois S, et al. Globus pallidus internus stimulation in primary generalized dystonia: a $\mathrm{H}_{2}{ }^{15} \mathrm{O}$ PET study. Brain 2004;127:1899-1908.

82. Silay K, Larson P, Starr P. Deep brain stimulator infections: incidence and management in a large series. Neurosurgery 2008 (in press).

83. Yianni J, Nandi D, Shad A, Bain P, Gregory R, Aziz T. Increased risk of lead fracture and migration in dystonia compared with other movement disorders following deep brain stimulation. J Clin Neurosci 2004;11:243-245.

84. Ghika J, Villemure JG, Fankhauser H, Favre J, Assal G, GhikaSchmid F. Efficiency and safety of bilateral contemporaneous pallidal stimulation (deep brain stimulation) in levodopa-responsive patients with Parkinson's disease with severe motor fluctuations: a 2-year follow-up review. J Neurosurg 1998;89:713-718.

85. Sellal F, Hirsch E, Barth P, Blond S, Marescaux C. A case of symptomatic hemidystonia improved by ventroposterolateral thalamic electrostimulation. Mov Disord 1993;8:515-518.
86. Loher TJ, Krauss JK, Burgunder JM, Taub E, Siegfried J. Chronic thalamic stimulation for treatment of dystonic paroxysmal nonkinesigenic dyskinesia. Neurology 2001;56:268-270.

87. Nikkhah G, Prokop T, Hellwig B, Lücking CH, Ostertag CB. Deep brain stimulation of the nucleus ventralis intermedius for Holmes (rubral) tremor and associated dystonia caused by upper brainstem lesions: report of two cases. J Neurosurg 2004;100:1079-1083.

88. Fukaya C, Katayama Y, Kano T, et al. Thalamic deep brain stimulation for writer's cramp. J Neurosurg 2007;107:977-982.

89. Taira T, Hori T. Stereotactic ventrooralis thalamotomy for taskspecific focal hand dystonia (writer's cramp). Stereotact Funct Neurosurg 2003;80:88-91.

90. Kleiner-Fisman G, Liang GS, Moberg PJ, et al. Subthalamic nucleus deep brain stimulation for severe idiopathic dystonia: impact on severity, neuropsychological status, and quality of life. J Neurosurg 2007;107:29-36.

91. Chou KL, Hurtig HI, Jaggi JL, Baltuch GH. Bilateral subthalamic nucleus deep brain stimulation in a patient with cervical dystonia and essential tremor. Mov Disord 2005;20:377-380.

92. Pastor-Gómez J, Hernando-Requejo V, Luengo Dos Santos A, Pedrosa-Sánchez M, Sola RG. Treatment of a case of generalized dystonia using subthalamic stimulation [In Spanish]. Rev Neurol 2003;37:529-531.

93. Detante O, Vercueil L, Krack P, Chabardes S, Benabid AL, Pollak P. Off-period dystonia in Parkinson's disease but not generalized dystonia is improved by high-frequency stimulation of the subthalamic nucleus. Adv Neurol 2004;94:309-314.

94. Sun B, Chen S, Zhan S, Le W, Krahl S. Subthalamic nucleus stimulation for primary dystonia and tardive dystonia. Acta Neurochir Suppl 2007;97:207-214.

95. Novak KE, Nenonene EK, Bernstein LP, Vergenz S, Cozzens JW, Rezak M. Successful bilateral subthalamic nucleus stimulation for segmental dystonia after unilateral pallidotomy. Stereotact Funct Neurosurg 2007;86:80-86.

96. Kupsch A, Klaffke S, Kühn AA, et al. The effects of frequency in pallidal deep brain stimulation for primary dystonia [Erratum in: J Neurol 2004;251:1031]. J Neurol 2003;250:1201-1205.

97. Grips E, Blahak C, Capelle HH, et al. Patterns of reoccurrence of segmental dystonia after discontinuation of deep brain stimulation. J Neurol Neurosurg Psychiatry 2007;78:318-320.

98. Zhang JG, Zhang K, Wang ZC, Ge M, Ma Y. Deep brain stimulation in the treatment of secondary dystonia. Chin Med J 2006; 119:2069-2074. 